\title{
Experimental Study on Mechanics and Pressure Sensitivity of Carbon Fiber RPC
}

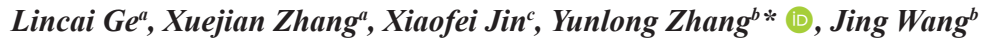 \\ ${ }^{a}$ Jilin Jianzhu University, School of Materials Science and Engineering, Changchun 130000, China \\ ${ }^{b}$ Jilin Jianzhu University, School of Transportation Science and Engineering, Changchun 130000, China \\ ${ }^{c}$ China Construction First Group Corporation Limited,Beijing 100161, China
}

Received: July 29, 2020; Revised: November 13, 2020; Accepted: November 27, 2020

\begin{abstract}
To study the mechanical properties and conductivity enhancement effect of carbon fiber (CF) on reactive powder concrete (RPC), this work systematically investigated the changes in the compressive strength, elastic modulus, Poisson's ratio, and pressure sensitivity of RPC under standard curing system. With age, CF content, and pressure sensitivity as parameters, the micro-method for scanning mechanism was used to study the effect mechanism of CF content on RPC. The experimental results showed that with the increase of carbon fiber content, poisson's ratio and compressive strength of carbon fiber RPC tended to increase first and then decrease. The elastic modulus decreased first and then increased, and $0.75 \%$ was the turning point of fiber content. With the increase of carbon fiber content, the resistivity decreases gradually, while the resistivity change rate (FCR) shows a trend of increasing and decreasing first, and there is a strong corresponding relationship between strain and FCR. When the CF content is $0.75 \%$, the maximum FCR is $38.8 \%$, which is increased by $33 \%$. the CF RPC with a CF content of $0.75 \%$ is the highest stress and strain sensitivity group, reaching $2.05 \%$ / Mpa and 513.7, respectively.
\end{abstract}

Keywords: Reactive powder concrete, Smart concrete, Carbon fiber, Pressure sensitivity, Mechanical properties.

\section{Introduction}

Damage detection and evaluation of concrete structures have been a hot topic in recent years ${ }^{1}$. Smart concrete is a relatively new civil engineering material. It can better sense the changes of stress and strain by adding an appropriate amount of conductor or semiconductor material to the cementbased material ${ }^{2}$. However, the shortcomings of smart concrete are also obvious, such as low mechanical properties, poor durability, short cycles, and easy damage ${ }^{3,4}$. The addition of fiber can significantly improve the mechanical properties and corrosion resistance of cement mortar ${ }^{5-7}$. To address the aforementioned disadvantages, carbon fiber (CF) is added to reactive powder concrete (RPC). RPC is a new cementbased composite material first developed by Bouygues in France in 1993 with Portland cement and various mineral admixtures as the cementing system ${ }^{8,9}$. The basic principle of RPC formulation is to increase the activity and fineness of each part of the material. Ultrafine powder such as silica fume is used for achieving a low water-to-gel ratio (W/B) to reduce porosity and obtain better strength ${ }^{10}$. RPC has the comprehensive advantages of light weight, high strength, high toughness, and high durability, making it applicable to petroleum, nuclear power, municipal, marine, and military facilities. With these advantages, RPC offers high social benefits ${ }^{11}$.

At present, local and international research have been conducted on the mechanical properties and electrical properties of CF cement-based composites. CF is a kind of microcrystalline

*e-mail zhangyunlong@jlju.edu.cn graphite material. CF has similar properties to carbon, such as stable structure, high temperature resistance, high tensile strength, large elastic modulus, corrosion resistance, small specific gravity, and strong toughness. CF is often used in the reinforcement and toughening of concrete materials, maintenance, and reinforcement ${ }^{12-14}$. Shu et al. ${ }^{15}$ studied the effect of CFs of different sizes on the mechanical properties of cement mortar and concluded that micro CFs can help large CFs to disperse and significantly improve the crack resistance of cement mortar. The addition of CF can greatly improve the compressive strength and reduce the resistivity of the cement matrix ${ }^{16}$. Rangelov et al. ${ }^{17}$ studied CFs of different sizes and incorporated them into the cement mortar mixture. The $28 \mathrm{~d}$ compressive strength increases by $11 \%$, and the $7 \mathrm{~d}$ tensile strength increases by $56 \%$. Park et al. ${ }^{18}$ incorporated $\mathrm{CF}$ content of $1 \%, 2 \%$, and $3 \%$ into cement mortar. They concluded that when the CF content is $1 \%, 2 \%$, and $3 \%$, the compressive strength of CFRCC is higher than that of ordinary cement mortar and increases respectively by $62 \%, 58.1 \%$, and $55.2 \%$. The tensile strength of CFRCC is improved compared to that of ordinary cement mortar by $103 \%, 172 \%$, and $255 \%$. Li et al. ${ }^{19}$ studied the effect of different CF content on the flexural strength of cement-based composites. The test results show that when the $\mathrm{CF}$ content is $0.8 \%, 1.2 \%$, and $1.6 \%$, the flexural strength of C-FRCM reaches 13.04 Mpa, 20.94 Mpa, and 14.41 Mpa. The bending strength is improved significantly.

With the development of construction and information technology, continuous innovation and reform of new materials, 
new processes and new technologies, real-time monitoring of safety performance of major civil engineering buildings, and self-diagnosis of building health have received increasing attention. The incorporation of CF not only improves the mechanical properties of concrete and cement mortar but also promotes the development of smart concrete. CF is considered to be the most suitable part for conductive concrete. Through uniaxial compression tests, Azhari and Banthia ${ }^{20}$ concluded that $\mathrm{CFs}$ and carbon nanotubes significantly increase the conductivity of cement-based materials. In addition, conductive concrete can sense microcracks and failures. For conductive concrete, many factors that affect electrical performance exist. Sassani et al. ${ }^{21}$ experimentally investigated the five influencing factors of conductive concrete (CF content, length, volume ratio of coarse and fine aggregate, expansion agent, and water content). They concluded that the CF content is the factor that exerts the greatest effect on resistivity, followed by the thickness aggregate ratio, fiber length and expansion agent, and moisture content. Han et al. ${ }^{22}$ used a direct current two-electrode method to measure the resistance and studied the effect of different $\mathrm{CF}$ content and length on the pressure sensitivity of CF concrete. The results show that the addition of CF significantly improves the mechanical properties of cement mortar. As the amount of fiber increases, the resistivity becomes lower, and the increase in fiber length is conducive to the establishment of an excellent conductive network ${ }^{19}$. Chiarello and Zinno ${ }^{23}$ studied the effect of CF content and length on the electrical conductivity of cement mortar. The results reveal that when the CF content is too high and exceeds the threshold current value, it has little effect on the electrical performance. Baeza et al. ${ }^{24}$ studied the effect of the amount of CF and the aspect ratio of the concrete on the electrical resistivity of the concrete. The experimental results indicate that the electrical conductivity is proportional to the length of the CF. As the aspect ratio increases, the penetration threshold will be generated in advance. Hambach et al. ${ }^{25}$ studied the effect of the amount of $\mathrm{CF}$ on the resistivity of conductive concrete. The experiments demonstrate that when the amount of $\mathrm{CF}$ increases from $0 \%$ to $1 \%$, the resistivity increases from 10-6 to 10-2. When the amount of CF exceeded $1 \%$, resistivity change is reduced significantly. As a non-metallic conductive material, carbon has good electrical conductivity.
Adding chopped CF to the cement matrix not only has good pressure sensitivity but also has a beneficial effect on the mechanical properties of RPC.

To date, research on intelligent cement-based composite materials at home and abroad is focused mainly on CF cement mortar with high water-to-binder ratio and CF concrete containing coarse aggregate. However, few reports exist on the pressure sensitivity and mechanical properties of CF RPC. The advantage of CF RPC is the combination of high strength and high sensitivity to meet the actual needs of engineering. In this test, the mineral admixture is a silica fume-ore powder-fly ash cementing material system. Due to the incorporation of mineral admixtures, on the one hand, can make full use of industrial waste, promote sustainable development; On the other hand, the internal structure of RPC could be optimized to effectively reduce the internal temperature rise of concrete and improve the anti-corrosion and anti-crack performance of RPC. The test explores the mechanical properties and pressure sensitivity of CF RPC with different amounts of CF under standard curing methods. The corresponding characteristics between the resistivity change rate (FCR) and external load can promote the further development of smart concrete.

\section{Test Overview}

\subsection{Test materials}

This study adopted P.II-grade 52.5 cement produced by Yatai Cement Industry of Jilin Province, China. The cement inspection report, which conforms to the general Portland Cement Inspection Standard (GB175-2007) ${ }^{26}$, is shown in Table 1. Silica fume produced produced by Shandong Boken Silicon Material Co., Ltd. was used, and the activity index was $116 \%$. Table 2 summarizes the silica fume composition. S95-grade mineral powder produced by Gongyi Longze Water Purification Materials of Henan Province, China were used. Table 3 lists the performance indicators. fly ash produced by Changchun Datang Second Thermal Power of Jilin Province, China. All of these were in accordance with the technical specifications of the Application of Mineral Admixtures (GB/T51003/2014) ${ }^{27}$. HSC polycarboxylic acid high-performance water reducing agent produced by Qingdao Hongxia Polymer Material Co., Ltd. was used,

Table 1. Chemical composition and physical properties of cement.

\begin{tabular}{|c|c|c|c|}
\hline \multicolumn{2}{|c|}{ Properties } & Standard Value & Actual Value \\
\hline \multirow{3}{*}{ Physical properties } & Specific surface area $\left(\mathrm{m}^{2} / \mathrm{kg}\right)$ & $\geq 300$ & 367 \\
\hline & Initial set (min.) & $\geq 45$ & 99 \\
\hline & Final set (min.) & $\leq 390$ & 145 \\
\hline \multirow{2}{*}{ Compressive strength } & 3 day $(\mathrm{MPa})$ & $\geq 23.0$ & 29.1 \\
\hline & 7 day $(\mathrm{MPa})$ & $\geq 52.5$ & \\
\hline \multirow{2}{*}{ Flexural strength } & 3 day $(\mathrm{MPa})$ & $\geq 4.0$ & 6.0 \\
\hline & 7 day $(\mathrm{MPa})$ & $\geq 7.0$ & \\
\hline \multirow{6}{*}{ Chemical properties } & Stability & Qualified & Qualified \\
\hline & Loss on ignition $(\%)$ & $\leq 3.5$ & 1.61 \\
\hline & $\mathrm{MgO}(\%)$ & $\leq 5.0$ & 0.98 \\
\hline & $\mathrm{SO}_{3}(\%)$ & $\leq 3.5$ & 2.62 \\
\hline & Insolubles (\%) & $\leq 1.5$ & 1.01 \\
\hline & $\mathrm{Cl}^{-}(\%)$ & $\leq 0.06$ & 0.007 \\
\hline
\end{tabular}


Table 2. Silica fume index parameters.

\begin{tabular}{ccccccc}
\hline Silica $/ \%$ & Ignition loss / \% & CI-(\%) & $\begin{array}{c}\text { Specific surface } \\
\text { area }\left(\mathbf{m}^{2} / \mathbf{g}\right)\end{array}$ & $\begin{array}{c}\text { Moisture } \\
\text { content } / \%\end{array}$ & $\begin{array}{c}\text { Water demand } \\
\text { ratio } / \%\end{array}$ & $\begin{array}{c}\text { Activity } \\
\text { index } / \%\end{array}$ \\
\hline 94.5 & 2.5 & 0.05 & 20 & 1.2 & 118 & 116 \\
\hline
\end{tabular}

Table 3. Mineral powder index parameters.

\begin{tabular}{|c|c|c|c|c|c|c|}
\hline Name & $\begin{array}{c}\text { Specific surface } \\
\text { area }\end{array}$ & $\begin{array}{l}\text { 7d activity } \\
\text { index } / \%\end{array}$ & $\begin{array}{l}\text { 28d activity } \\
\text { index } / \%\end{array}$ & Density $/\left(\mathrm{g} / \mathbf{c m}^{3}\right)$ & Ignition loss / \% & $\begin{array}{c}\text { Moisture } \\
\text { content / \% }\end{array}$ \\
\hline $\begin{array}{l}\text { S95 mineral } \\
\text { powder }\end{array}$ & 409 & 83 & 98 & 2.9 & 1.07 & 0.1 \\
\hline
\end{tabular}

Table 4. Index parameters of carbon fiber.

\begin{tabular}{cccccc}
\hline Density $/\left(\mathrm{g} / \mathrm{cm}^{3}\right)$ & $\begin{array}{c}\text { Tensile } \\
\text { strength } / \mathrm{MPa}\end{array}$ & $\begin{array}{c}\text { Elongation at } \\
\text { break } / \%\end{array}$ & Meltingpoint $/{ }^{\circ} \mathrm{C}$ & $\begin{array}{c}\text { Tensile modulus of } \\
\text { elasticity } / \mathbf{G P a}\end{array}$ & Length/mm \\
\hline 1.88 & $\geq 2000$ & $\geq 2.5$ & 750 & $\geq 85$ & 7 \\
\hline
\end{tabular}

Table 5. Proportion of CF RPC

\begin{tabular}{cccccccc}
\hline $\begin{array}{c}\text { water-binder } \\
\text { ratio(W/B) }\end{array}$ & Cementing material: Silica fume: Slag powder: Fly ash & superplasticizer/\% & $\begin{array}{c}\text { Sand and } \\
\text { binder ratio }\end{array}$ & $\begin{array}{c}\text { Carbon fiber } \\
\text { content/\% }\end{array}$ \\
\hline 0.18 & 1 & 0.2 & 0.1 & 0.1 & 3 & 0.9 & 0 \\
\hline 0.18 & 1 & 0.2 & 0.1 & 0.1 & 3 & 0.9 & 0.5 \\
\hline 0.18 & 1 & 0.2 & 0.1 & 0.1 & 3 & 0.9 & 0.75 \\
\hline 0.18 & 1 & 0.2 & 0.1 & 0.1 & 3 & 0.9 & 1 \\
\hline 0.18 & 1 & 0.2 & 0.1 & 0.1 & 3 & 0.9 & 1.25 \\
\hline
\end{tabular}

and the water-reducing rate was $28.5 \%$. The selected quartz sand was natural river sand. Such sand was obtained in Jilin Province. The sand with the particle size below $1.18 \mathrm{~mm}$ was selected as the test sand. The labor cost of such sand was reduced in comparison with that of the sieved fine sand. The fineness modulus was 2.158 , which is a fine sand value. The CF produced by a company in Shandong was used. Table 4 presents the performance indexes.

\subsection{Preparation and curing of test pieces}

1. The RPC mix ratio is shown in Table 5. To be close to the actual project, the test did not add dispersant but changed the stirring process to make the $\mathrm{CF}$ uniformly dispersed. First, the weighed sand, cement, silica fume, fly ash and mineral powder are put into the HJW-60 single-horizontal shaft forced concrete mixer with the rotating speed of 45 RPM for 1 minute. The fiber is then added and stirred for 2 min. Following, 90\% of the water-reducing agent is put in the weighed water and stirred for $1 \mathrm{~min}$. After that, the remaining $10 \%$ of the waterreducing agent is added, and stirring is continued for $3 \mathrm{~min}$. The test uses $100 \mathrm{~mm} \times 100 \mathrm{~mm} \times 100 \mathrm{~mm}$ concrete compressive strength standard test pieces, $100 \mathrm{~mm} \times 100 \mathrm{~mm} \times 300 \mathrm{~mm}$ concrete prism compressive test pieces, elastic modulus test pieces, and pressuresensitive test pieces. The test piece is made and vibrated in accordance with the specifications in "Reactive Powder Concrete" (GB/T 31387-2015)28. After the artificial vibration is completed, the test piece is placed on the vibration table and shaken until no obvious air bubbles overflow. The time is between $45 \mathrm{~s}$ and $75 \mathrm{~s}$. After molding, the test pieces are placed in a standard curing box with a temperature of $20^{\circ} \mathrm{C}$ and a humidity of $95 \%$ for curing. After $24 \mathrm{~h}$, the molds are disassembled and numbered, and the test pieces are placed in the curing box for curing to 28 days.

2. Elastic modulus and Poisson's ratio test: 100100300 prisms were used for the test specimens and loaded on a YAR-200 pressure testing machine. According to GB/T5008-2010, the 28d static compression elastic modulus and Poisson's ratio are determined. The calculation formula of concrete elastic modulus is expressed as Formula 1. During the elastic modulus test, the axial and radial strains corresponding to $f$ and fo during each loading process are recorded. The Poisson's ratio is calculated according to Formula 2.

$E_{c}=\frac{F_{a}-F_{0}}{A} \times \frac{L}{\Delta n}$

$V=\varepsilon_{j x} / \varepsilon_{z x}$

Where

Ec-Compressive elastic modulus of concrete (Mpa)

$\mathrm{V}$-Poisson's ratio

F0 - Initial load at stress of $0.5 \mathrm{Mpa}(\mathrm{KN})$

$\mathrm{Fa}$ - Load at stress of $1 / 3$ compressive strength (KN)

A-Pressure area of test piece $(\mathrm{mm} 2)$

$\mathrm{L}$-Measuring gauge distance $(\mathrm{mm})$

$\Delta \mathrm{n}$-Mean value of deformation difference $(\mathrm{mm})$ on both sides of the specimen under the action of $\mathrm{Fa}$ and $\mathrm{F} 0$ during the last loading

$\varepsilon j \mathrm{x}$-Absolute value of radial strain difference of test piece 
EZX - Absolute value of axial strain difference of test piece

3. Pressure sensitivity test: The load is carried out on the YAR-2000 pressure test machine. The strain arrangement, specimen and loading diagram are shown in Figure 1. The resistance test uses the VC8900 multi-function meter and the direct current two-electrode method for testing. The strain is a DH-3817 static strain gauge, the collection frequency is $20 \mathrm{HZ}$, and the loading speed is $5 \mathrm{KN} / \mathrm{s}$. During loading, load, resistance, and strain values are collected simultaneously. The resistivity is shown in Formula 3, and the resistance change rate is expressed as Formula 4. The formulas for stress and strain sensitivity are given in (5) and (6).

$\rho=R A / L$

$F C R=\left(\rho-\rho_{0}\right) / \rho_{0}$

Stress sensitivity $=|F C R| / \sigma$

Strain sensitivity $=|F C R| / \varepsilon$

\section{Where}

$\mathrm{R}$-Resistance of test piece

A-Section electrode area

L-Length between two electrodes of test piece

$\rho$-Resistivity under corresponding load during test

$\rho_{0}$-Resistivity of the test piece before loading

FCR - resistivity change rate

$\sigma$-stress along the loading direction

$\varepsilon$-radial strain

\section{Analysis of CF RPC Test Results}

\subsection{Test results}

A large number of tests were performed on the basic mechanical properties of CF RPC, including experimental studies on the compressive strength of cube and prism under standard curing regimes at $7 \mathrm{~d}$ and $28 \mathrm{~d}$. Table 6 summarizes the results of various tests of CF RPC.

\subsection{Analysis of compressive strength test results and failure morphology}

When CF is not added to RPC, the concrete will continue to drop slag during the load increase, and then brittle failure will occur directly after the loud noise. After the incorporation of $\mathrm{CF}$, the concrete gradually develops cracks from both sides along with the increasing load. At the moment when the ultimate load is reached, the crack will also be loud, but the integrity of the specimen is better than that of the unincorporated fiber, as shown in Figures $2 \mathrm{~b}$ and $2 \mathrm{~d}$. The test results show that the brittleness characteristics of RPC can be significantly alleviated by the incorporation of $\mathrm{CF}$. With the increase of the amount of CF, the brittle failure is continuously slowed down. The bond between CF and cement matrix is relatively strong, which increases the energy consumption when the fiber is pulled out. With the increase of the load, the phenomenon of slag dropping and peeling appears, but the CF RPC can maintain better integrity, improve brittle failure, and have certain plastic failure characteristics.

When the CF content does not reach the agglomeration limit, the combined effect of $\mathrm{CF}$ in the cement collective to

Table 6. Summary of mechanical properties of CF RPC

\begin{tabular}{cccccc}
\hline $\begin{array}{c}\text { Carbon fiber } \\
\text { content /\% }\end{array}$ & $\begin{array}{c}\text { 7d cube } \\
\text { compressive } \\
\text { strength / Mpa }\end{array}$ & $\begin{array}{c}\text { 28d cube } \\
\text { compressive } \\
\text { strength / Mpa }\end{array}$ & $\begin{array}{c}\text { 28d prism } \\
\text { compressive } \\
\text { strength / Mpa }\end{array}$ & Fp/Fcu & $\begin{array}{c}\text { Elastic } \\
\text { Modulus/Gpa } \\
\text { Poisson's ratio }\end{array}$ \\
\hline 0 & 73.19 & 82.09 & 78.51 & 0.95 & 0.194 \\
\hline 0.5 & 77.07 & 91.98 & 85.23 & 0.92 & 38.2 \\
\hline 0.75 & 87.41 & 101.81 & 91.54 & 0.90 & 37.5 \\
\hline 1.0 & 73.48 & 93.74 & 86.38 & 0.92 & 37.9 \\
\hline 1.25 & 71.24 & 84.34 & 83.02 & 0.99 & 0.253 \\
\hline
\end{tabular}

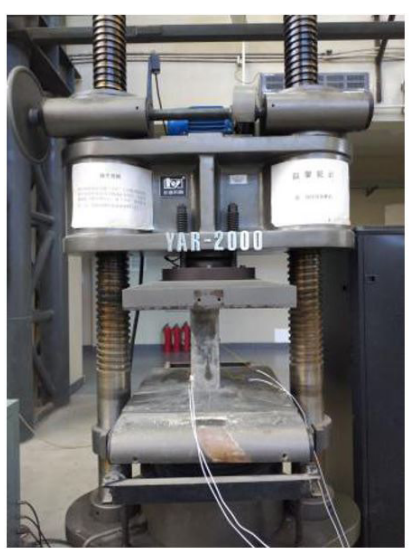

(a) Loading system

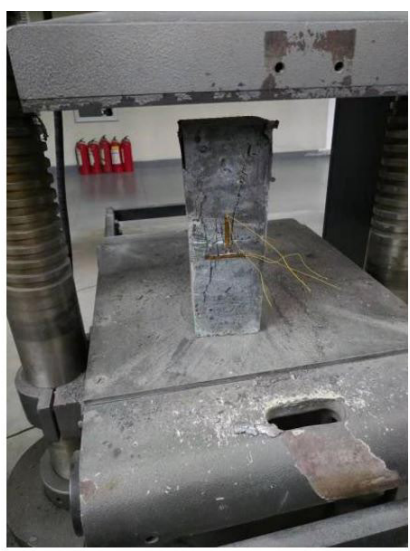

(b) CF RPC specimen

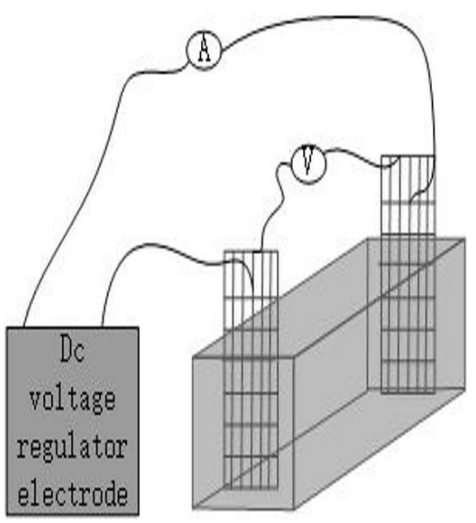

(c) Two electrode method

Figure 1 . Specimen making and loading methods 
fully exert the cracking resistance effect and improve the weak interface makes the addition of fibers effectively improve the RPC compression strength. As shown in Figures 3a and 3b, the compressive strength change curves at $7 \mathrm{~d}$ and $28 \mathrm{~d}$ are relatively consistent. At $7 \mathrm{~d}$, the CF content is $0.5 \%$, and the compressive strength is increased by $5.3 \%$. At $0.75 \%$, the compressive strength increased by $19.4 \%$. At $28 \mathrm{~d}$, the increase

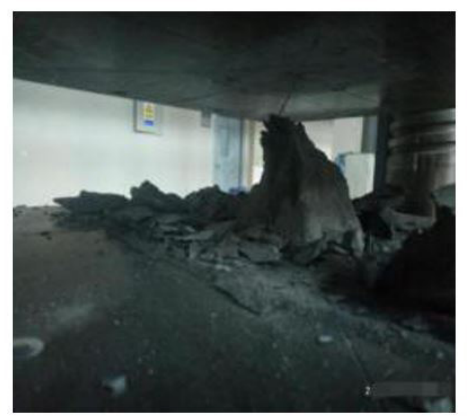

(a) Failure pattern of prime RPC cube

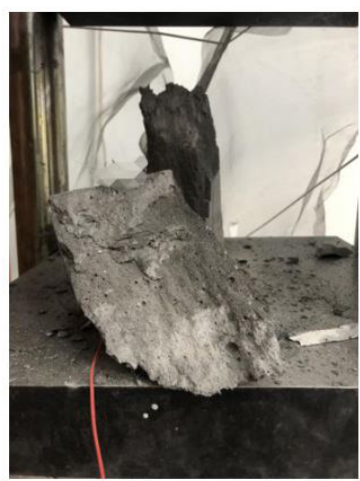

(c) Failure morphology of prime RPC prism

Figure 2. Destruction of plain RPC and CF RPC in compressive strength is $2.7 \%$ to $23.1 \%$. Compared with the $7 \mathrm{~d}$ age, the maximum compressive strength is reached when the CF content is $0.75 \%$. When the CF content is greater than the critical value of $0.75 \%$, the agglomeration of the internal fibers of the RPC matrix begins to occur, leading to internal defects and reduced compressive strength. When the CF content is $1.0 \%$, the compressive strength of

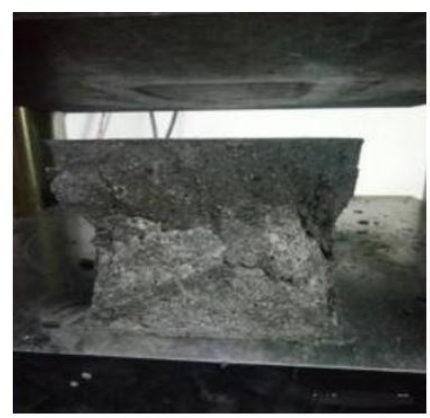

(b) CF RPC cube failure morphology

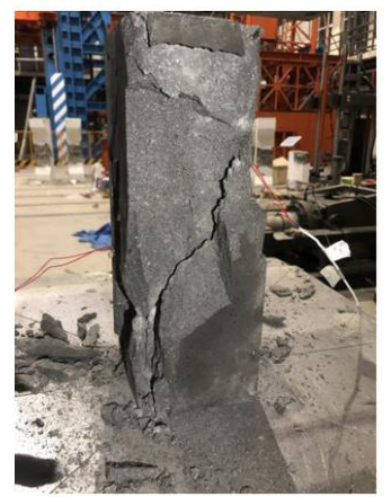

(d) Failure mode of CF RPC prism

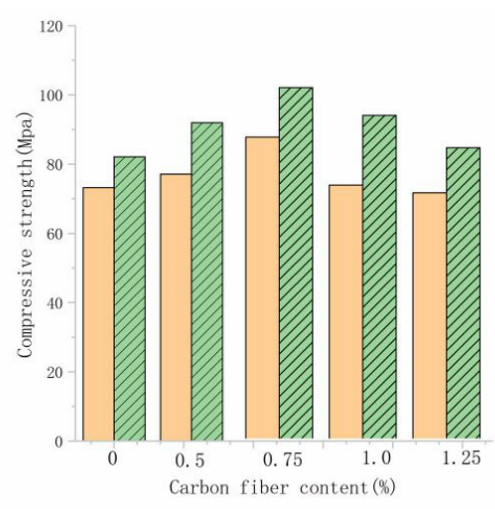

(a) Compressive strength of $7 \mathrm{~d}$ and $28 \mathrm{~d} \mathrm{CF}$

$$
\mathrm{RPC}
$$

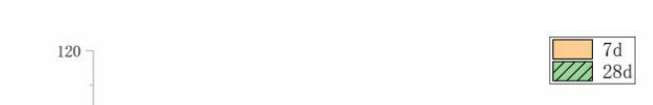

Figure 3. Compressive strength and compressive strength growth ratio of $7 \mathrm{~d}$ and $28 \mathrm{~d}$ CF RPC

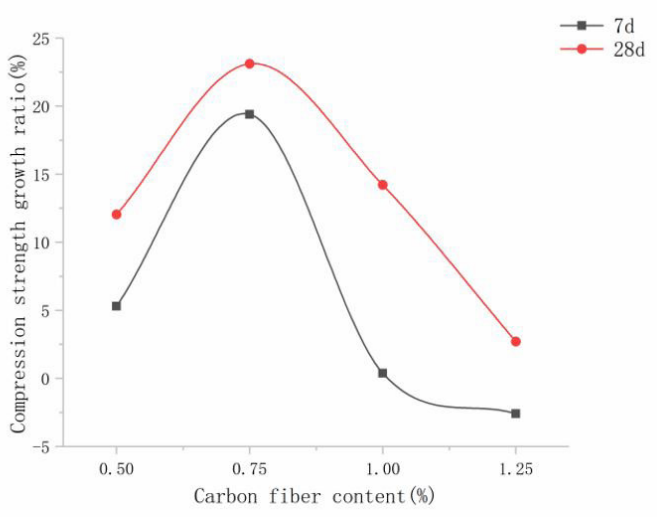

(b) Compressive strength growth ratio of $7 d$ and $28 \mathrm{~d}$ CF RPC 
CF RPC increases by $0.38 \%$. When the CF content is 1.25 , the RPC matrix agglomeration is serious, the defects are further increased, and the compactness is decreased. The compressive strength is increased by $2.6 \%$.

\subsection{Stress-strain curve analysis of CF RPC}

At present, most structures work in the elastic range. Thus, the test adopts the rising section of the CF RPC stress-strain curve. As shown in Figure 4, the axial stress-strain curves of RPCs with different CF contents under a single-cycle compressive stress are similar in shape. When the axial stress is $0-0.1 \sigma_{p}$, it is the first stage, that is, compact stage. In this stage, the microcracks inside the RPC are gradually closed, and the shape of the axial stress-strain curve is a straight line. When the stress is $0.1-0.6 \sigma_{p}$, this stage is called the elastic stage, and the axial and radial stress-strain curves are approximately straight lines. Owing to the different amounts of CF, the time at which the CF RPC reaches the end of the elastic phase varies. When the stress is $0.6-0.9 \sigma_{p}, C F R P C$ enters the third stage, which is the plastic stage. At this stage, the CF and the cement matrix are co-stressed. As the stress increases, the CF is continuously pulled out and cut. $\mathrm{CF}$ gives full play to the role of reinforcement and crack resistance, resulting in a strain growth rate much greater than the strain. Taking the CF RPC content of $0.75 \%$ as an example for analysis, in the $0.6-0.9 \sigma_{p}$ stage, the stress increases from 55.8 Mpa to $83.7 \mathrm{Mpa}$, which is a $50 \%$ increase, and the radial strain increases from 1611 to 2753 , an increase of $70.88 \%$. After $\sigma>0.9 \sigma_{p}$, the fourth stageunstable development stage - is where plastic deformation increases sharply, slope decreases significantly, and axial and radial strain increases significantly. When the stress reaches $\sigma_{p}$, the CF RPC increases with the increase of microcracks, the CF stops the work, and then the CF RPC test piece is destroyed with a loud noise.

\subsection{Analysis of RPC elastic modulus and Poisson's ratio of $C F$}

As shown in Figure 5, the elastic modulus of RPC under different $\mathrm{CF}$ content changes in a broken line. The elastic modulus of plain RPC is $41.7 \mathrm{Gpa}$. When the CF content is $0.5 \%, 0.75 \%, 1.0 \%$, and $1.25 \%$, the elastic modulus of $\mathrm{CF}$ $\mathrm{RPC}$ is $38.2 \mathrm{Gpa}, 37.5 \mathrm{Gpa}, 37.9 \mathrm{Gpa}$, and $39.4 \mathrm{Gpa}$.

As can be seen from Figure 4, considering the elastic stage of the axial stress-strain curve, the slopes of the CF RPC are all smaller than those of the plain RPC. When the CF content is $0.5 \%, 0.75 \%, 1.0 \%$, and $1.25 \%$, the elastic modulus of CF RPC is reduced by $7.2 \%, 8.9 \%, 8.0 \%$, and $4.3 \%$, respectively. Owing to the incorporation of $\mathrm{CF}$, the elastic modulus tends to decrease. When the CF content is in the range of $0 \%$ to $0.75 \%$, the elastic modulus gradually decreases. When the amount of $\mathrm{CF}$ is in the range of $0.75 \%$ to $1.25 \%$, the elastic modulus of CF RPC rises to a different extent than when the amount of fiber is $0.75 \%$. The incorporation of CF has a certain effect on the Poisson's ratio of RPC. In this test, the compressive stress is only $1 / 3 \sigma_{p}$. At this lower stress level, RPC is basically in the elastic stage. CF plays a role in the deformation of RPC. The Poisson's ratio of prime RPC is 0.194 . When the CF content is $0.5 \%$, $0.75 \%, 1.0 \%$, and $1.25 \%$, the Poisson's ratio of CF RPC is higher than that of plain RPC, that is, $24.7 \%, 30.4 \%$, $28.8 \%$, and $22.6 \%$, respectively. When the CF content is in the range of $0 \%$ to $0.75 \%$, the Poisson's ratio of carbon fiber RPC is gradually higher than that of plain RPC. In the range of $0.75 \%$ to $1.25 \%$, the Poisson's ratio of CF RPC decreased to different degrees when the content of CF was $0.75 \%$. This is mainly due to the high elastic modulus of CF that restrains the lateral deformation of the RPC specimen and reduces the lateral strain. When the CF content is low, the incorporation of $\mathrm{CF}$ presents a positive effect on the RPC matrix, whereas when the CF content exceeds the optimal content, the internal defects of the cement matrix will gradually emerge, resulting in a negative effect on the strength and toughness of RPC.

In order to study the interfacial bonding property and crack resistance of carbon fiber in cement matrix. As shown in Figure 6a, carbon fiber is closely bonded to RPC matrix, and the collective adhesion between carbon fiber and cement is relatively ideal. The carbon fiber is broken in the cement collective instead of being pulled out. This is because carbon fiber was dispersed in the RPC matrix and formed a fiber network, which prevented the development and connection of cracks inside RPC, thus achieving the effect of improving strength and cracking resistance. As shown in Figure 6b,

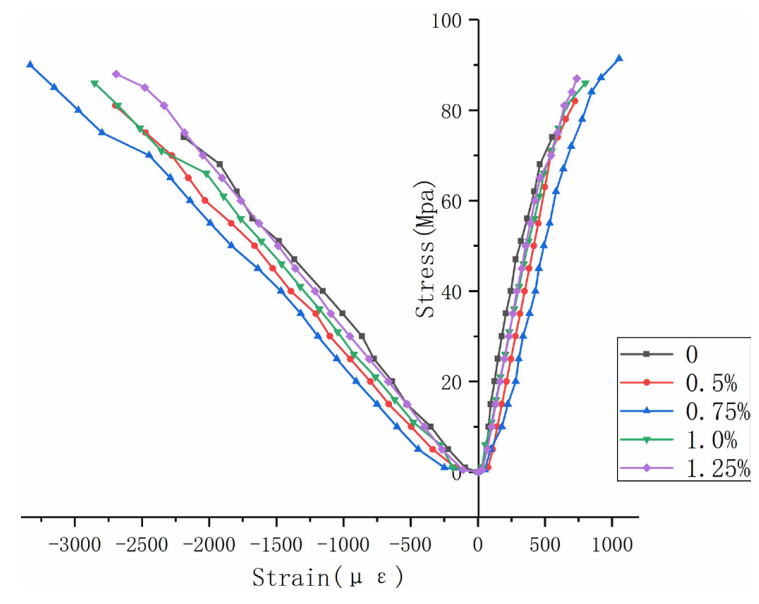

Figure 4. Stress-strain curves of CF RPC with different CF content

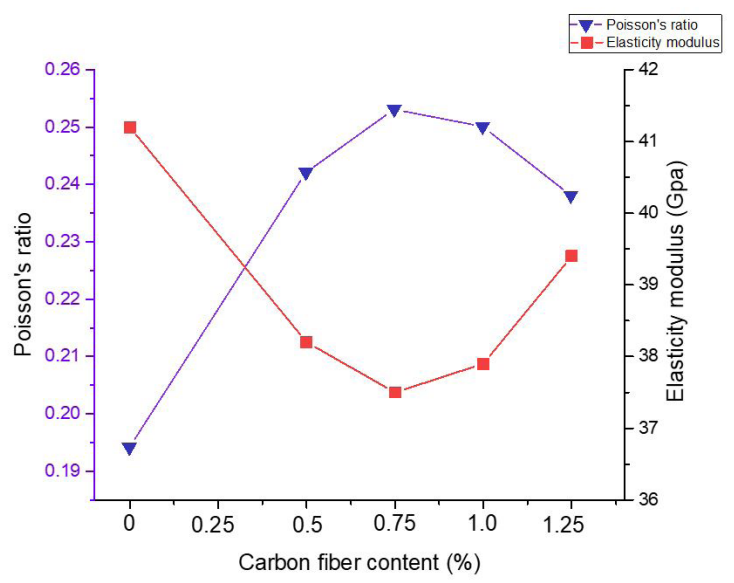

Figure 5. Elastic modulus and Poisson's ratio at different CF content 


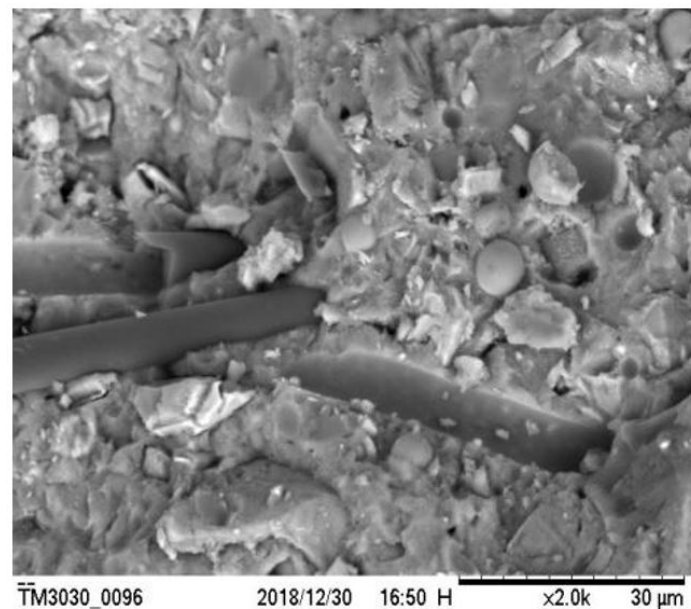

(a) Fiber and matrix bonding state

Figure 6. Microstructure of CF RPC

under the action of axial stress, the CF bears part of the stress and absorbs part of the energy. The cement matrix crack gradually develops. When the crack develops to the fiber, the driving force of the crack is blocked and the crack stops developing. Meanwhile, the crack penetration can be effectively prevented, so that the mechanical properties of carbon fiber RPC can generate gain effect.

\section{Electrical Performance Research}

\subsection{CF RPC resistivity test results and analysis}

Table 7 is the summary of the results of carbon fiber RPC resistivity test under different content at $28 \mathrm{~d}$. Owing to the high density of CF RPC, the overall conductivity of the structure is low, which results in a higher resistivity of RPC. The relationship between resistivity and CF content is shown in Figure 7. When the CF content in RPC is from $0 \%$ to $0.5 \%$, the resistivity of CF RPC is significantly reduced by $75.3 \%$. When the CF content was increased from $0.5 \%$ to $0.75 \%$, the resistivity of the CF RPC decreased by $97.7 \%$, and the resistivity decreased with the increase of the $\mathrm{CF}$ content. As shown in Figure 7, the percolation threshold of CF RPC is $0.5 \%-0.75 \%$. As RPC has a very low waterto-binder ratio, with the further increase of the $\mathrm{CF}$ content, $\mathrm{CF}$ agglomeration is serious and internal defects increase, which is not conducive to the overlap between CF. When the $\mathrm{CF}$ content is $1 \%$, the resistivity is increased by $114.2 \%$ compared with $0.75 \%$. When the CF content is from $1.0 \%$ to $1.25 \%$, the RPC resistivity increases by $19.0 \%$.

\subsection{FCR law under monotonic loading}

(1) Change law of stress, strain, and FCR under different CF content

Figure $8 \mathrm{a}$ indicates that within $0-40 \mathrm{Mpa}, \mathrm{FCR}$ gradually increases as the load gradually increases. When the CF content is $0.5 \%$, the maximum FCR is $29.1 \%$. When the $\mathrm{CF}$ content is $0.75 \%$, the maximum FCR is $38.8 \%$. When the $\mathrm{CF}$

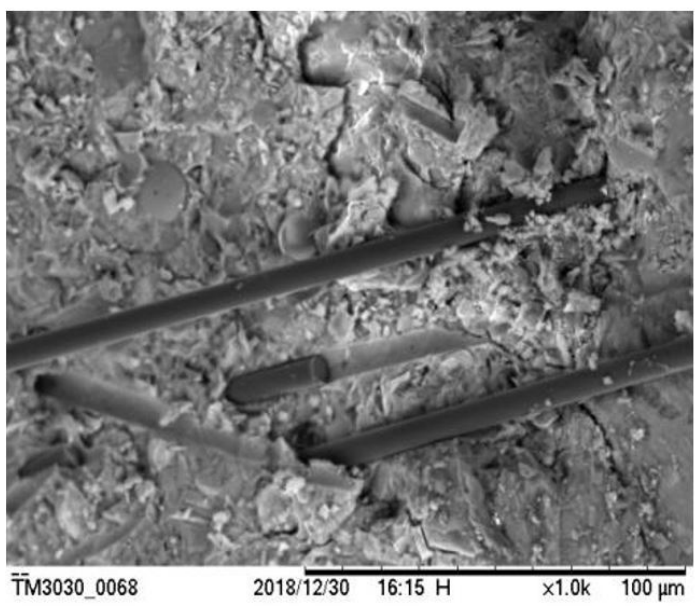

\section{(b) Impede crack development}

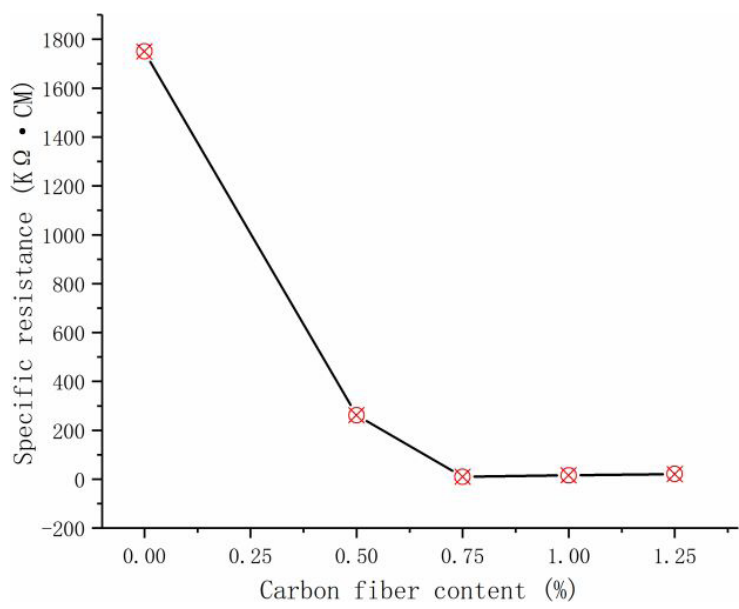

Figure 7. Relationship between resistivity of CF RPC and CF content

content is $1.0 \%$, the maximum FCR is $37.1 \%$. When the CF content is $1.25 \%$, the maximum FCR is 23.5 . When the $\mathrm{CF}$ content is $0 \%$, only the cement particles in the RPC matrix are conductive, and no obvious pressure sensitivity is noted under the action of the classification load. After adding CF, its conductive principle is contact and non-contact conductivity between carbon fibers. With the continuous increase of the load, the CF is continuously overlapped. At the same time, the electronic transition is gradually performed. When the CF content is $0.5 \%$, the probability of overlap between the two CFs is very low, the barrier width increases, and the electronic transition is difficult. When the CF content is $0.75 \%$, the FCR is the maximum. However, as the CF content is gradually increased, the overlap probability and the degree of overlap between the CF are significantly increased, and the electronic transition is relatively easy, causing the FCR to gradually decrease.

Figure $8 \mathrm{~b}$ is a graph of the strain-FCR effect of CF RPC under different $\mathrm{CF}$ content under the stress of 0-40 Mpa. 
Table 7. CF RPC resistivity at $28 \mathrm{~d}$.

\begin{tabular}{|c|c|c|c|c|c|}
\hline Carbon fiber content $/ \%$ & 0 & 0.5 & 0.75 & 1.0 & 1.25 \\
\hline Resistivity $(\mathrm{K} \Omega \cdot \mathrm{CM})$ & 1750 & 462 & 9.8 & 16.4 & 21.2 \\
\hline
\end{tabular}

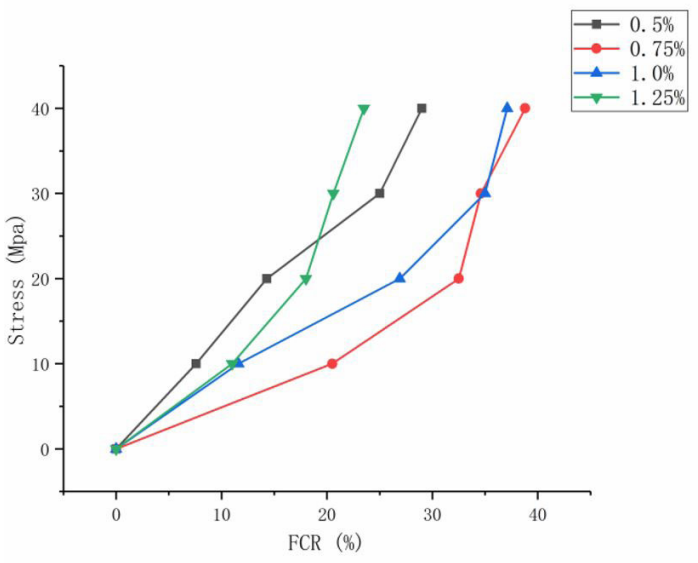

(a) Stress-FCR influence curve

Figure 8. Effect of CF content on RPC pressure sensitivity

Compared with carbon RPC and plain RPC, when the CF content is $0.5 \%, 0.75 \%, 1.0 \%$, and $1.25 \%$, under $10 \mathrm{Mpa}$, the strain and FCR of CF RPC are $496.2 \mu \varepsilon, 7.6 \% ; 531.8 \mu \varepsilon$, $20.5 \% ; 479.9 \mu \varepsilon, 11.6 \%$; and $399.2 \mu \varepsilon, 11 \%$. Under 20 Mpa, the strain and FCR of CF RPC are $800.2 \mu \varepsilon, 14.3 \%$; $906 \mu \varepsilon, 32.5 \%$; $761.3 \mu \varepsilon, 26.9 \%$; and $666.5 \mu \varepsilon, 18.1 \%$. Under $30 \mathrm{Mpa}$, the CF RPC strain and FCR are $1100.9 \mu \varepsilon, 25 \%$; $1190.2 \mu \varepsilon, 34.6 \% ; 1043.8 \mu \varepsilon, 35 \%$; and $952.2 \mu \varepsilon, 20.6 \%$. Under $40 \mathrm{Mpa}$, the CF RPC strain and FCR are $1391.9 \mu \varepsilon$, $29 \% ; 1465.2 \mu \varepsilon, 38.8 \% ; 1322.1 \mu \varepsilon, 37.1 \%$; and $1212.3 \mu \varepsilon$, $23.5 \%$. The strain and FCR increase with the increase of the load. When the CF content is $0.75 \%$, the FCR changes the most. The FCR and strain of CF RPC have a strong corresponding relationship. Under the same load, the FCR and strain relationship increases when the CF content is within the $0.5 \%-0.75 \%$ and gradually decreases when the $\mathrm{CF}$ content is within the range of $1.0 \%-1.25 \%$. As the degree of change in FCR increases, so does the strain. In the range of $0 \mathrm{Mpa}$ to $40 \mathrm{Mpa}$, the strain and FCR gradually increase as the load increases. CF RPC has a good correspondence between strain and FCR under monotonic loading and has stable and regular sensing performance.

\subsection{Correlation between strain and resistivity change rate}

To verify the correlation between the change rate of RPC resistivity and strain, this experiment performed a quadratic function fitting on the $\mathrm{CF}$ at $0.5 \%, 0.75 \%, 1.0 \%$, and $1.25 \%$, as shown in Figure 9.

$y=a x+b$

According to existing engineering experience, the $200 \mathrm{KN}$ load meets the actual engineering requirements. Therefore, FCR under $0 \mathrm{KN}, 100 \mathrm{KN}$, and $200 \mathrm{KN}$ load

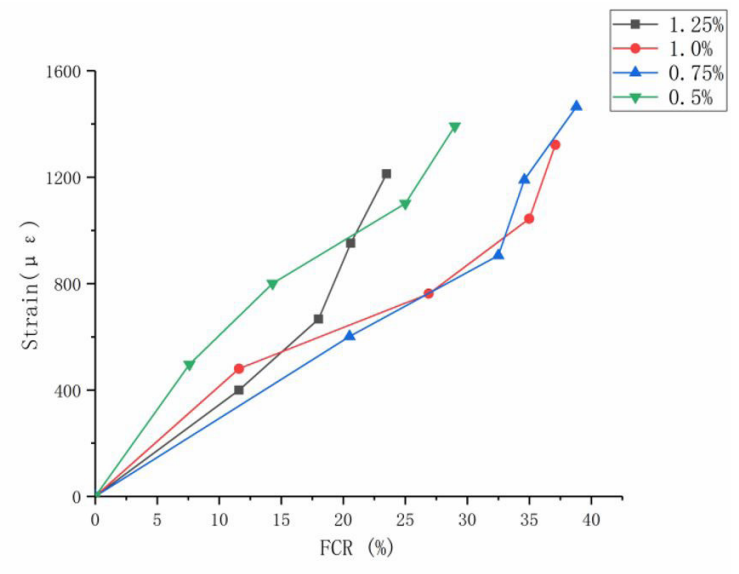

(b) Strain-FCR influence curve

is used for linear fitting. With the change rate of resistivity on the $\mathrm{y}$-axis and the strain on the $\mathrm{x}$-axis, the curves of strain and FCR under different CF content are drawn. After three-point fitting, the equation is obtained, that is, $\mathrm{y}=\mathrm{ax}$ $+b$, where $a$ and $b$ are the parameters of the equation under different loads. The parameters and correlation coefficients of the linear fitting equation are shown in Table 8. During the uniaxial compression test of RPC, the change rate of resistivity is positively related to the strain. When the CF content is $0.5 \%, 0.75 \%, 1.0$, and $1.25 \%$, the $\mathrm{R} 2$ values are $0.985,0.998,0.968$, and 0.999 , respectively. The fitting equations are $\mathrm{y}=50 \mathrm{x}+24.2, \mathrm{y}=20 \mathrm{x}-5.1, \mathrm{y}=28.8 \mathrm{x}+45.4$ and $\mathrm{y}=43 \mathrm{x}+2.8$, respectively. When the CF content is $0.75 \%$ and $1.25 \%$, the correlation between FCR and strain is high, and $\mathrm{R} 2$ is greater than 0.99 . In the range of $0 \mathrm{Mpa}$ to $20 \mathrm{Mpa}$, when the CF content is $0.5 \%, 0.75 \%, 1.0 \%$, and $1.25 \%$, the degree of change in FCR increased by $14.3 \%, 32.5 \%$, $26.9 \%$, and $18 \%$ respectively compared to that of plain RPC. When the CF content is $0.75 \%$, the FCR of CF RPC changes the most and sensitivity is at the highest. When the CF content is $1.25 \%$, the compressive strength is lower than the $0.5 \%, 0.75 \%$, and $1.0 \%$ compressive strength, but the fitting degree is the best. For CF RPC, no correlation is found between compressive strength and degree of fit. The values of R2 under different CF content are all greater than 0.96 , indicating that the resistivity characteristics and strain can be expressed by linear equations.

\subsection{Stress and strain sensitivity}

(1) Perceptual performance under monotonic loading

As shown in Figures 10a and 10b, the stress and strain sensitivity of CF RPC under different stresses are different, and the change in RPC test piece is reflected from the sensitivity value. When $\sigma=10 \mathrm{Mpa}$, as the amount of $\mathrm{CF}$ 


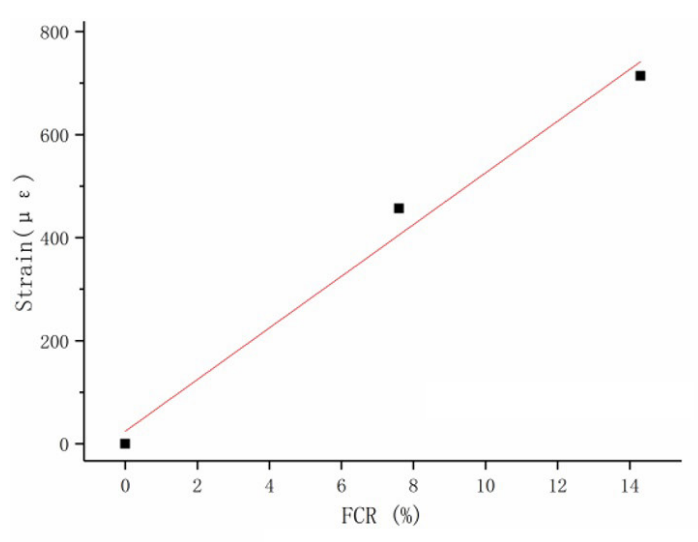

(a) $0.5 \%$

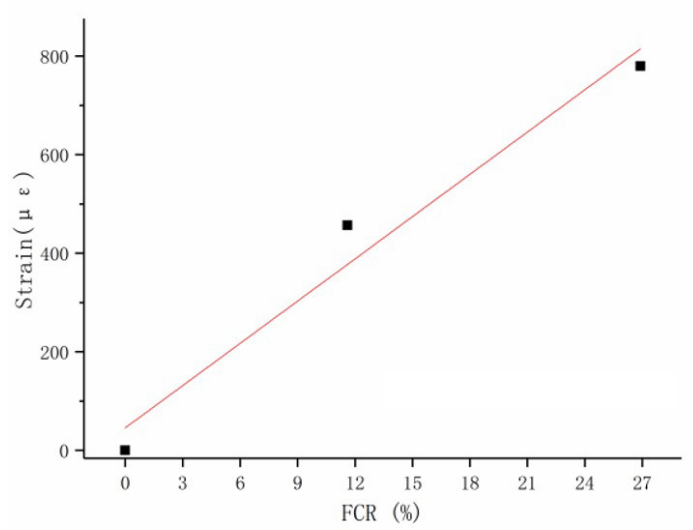

(c) $1.0 \%$

Figure 9. FCR and strain fitting curves for different CF content

Table 8. Parameters of the fitting equation

\begin{tabular}{cccc}
\hline $\begin{array}{c}\text { Carbon fiber } \\
\text { content } / \%\end{array}$ & $\mathbf{R}^{2}$ & $\mathbf{a}$ & $\mathbf{b}$ \\
\hline $0.5 \%$ & 0.985 & 50 & 24.2 \\
\hline $0.75 \%$ & 0.998 & 20 & -5.1 \\
\hline $1.0 \%$ & 0.968 & 28.8 & 45.4 \\
\hline $1.25 \%$ & 0.999 & 43 & 2.8 \\
\hline
\end{tabular}

is increased, the sensitivity of stress and strain increases first and then decreases. When the CF content is $0.75 \%$, it is the highest stress and strain sensitivity group, reaching $2.05 \% / \mathrm{Mpa}$ and 386.1, respectively. The stress and strain sensitivity at this CF content is higher than the stress and strain sensitivity of the composite carbon nanotubes and carbon black cement-based materials studied by Han and $\mathrm{Ou}^{29} 1.35 \% / \mathrm{Mpa}$ and 227 . When the CF content is $1.0 \%$, the highest stress and strain sensitivity reach $1.35 \% / \mathrm{Mpa}$ and 353.4, respectively. When the CF content is $0.5 \%$, the highest stress and strain sensitivity are $0.83 \%$ /Mpa and 227.4 . When the CF content is $1.25 \%$, the highest stress and strain sensitivity are $1.1 \% / \mathrm{Mpa}$ and 275.6 .

As the load increases, the magnitude of the change in stress and strain sensitivity gradually decreases. Under the

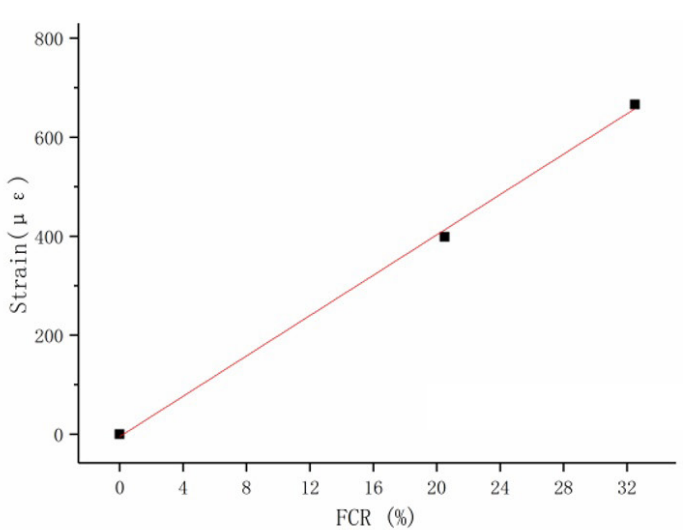

(b) $0.75 \%$

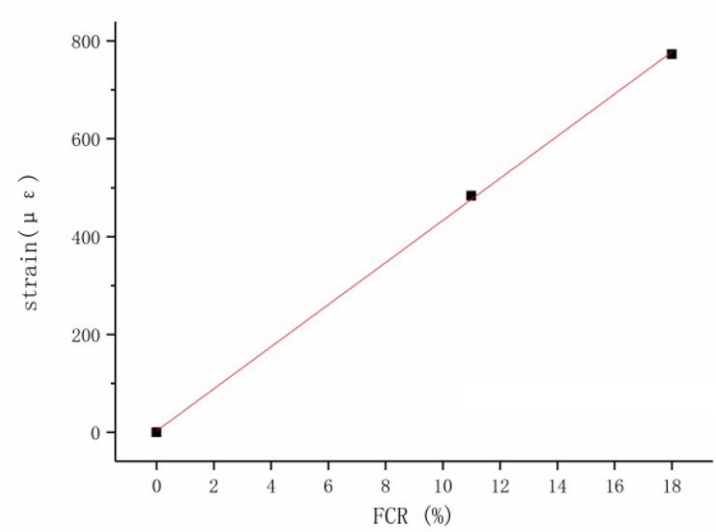

(d) $1.25 \%$

action of $\sigma=10 \mathrm{Mpa}$, compared with the benchmark group of $\mathrm{RPC}$ with $0.5 \% \mathrm{CF}$ content, when the CF content is $0.75 \%$, $1.0 \%, 1.25 \%$, the increase in stress sensitivity of CF RPC compared with the benchmark group is $169.7 \%, 52.6 \%$, and $44.7 \%$. The increase in strain sensitivity is $152.3 \%, 58.1 \%$, and $80.2 \%$. Under the action of $\sigma=20 \mathrm{Mpa}$, the increase in stress sensitivity is $126.4 \%, 87.5 \%$, and $25 \%$ and the increase in strain sensitivity is $101.1 \%, 98.3 \%$, and $51.6 \%$. The increase of stress sensitivity under $\sigma=30 \mathrm{Mpa}$ is $38.5 \%$, $40.9 \%$, and $-16.8 \%$. The increase in strain sensitivity is $25.4 \%, 47.5 \%$, and $-4.8 \%$. Under the action of $\sigma=40 \mathrm{Mpa}$, the stress sensitivity increases are $32.8 \%, 26.1 \%$, and $-20.1 \%$; the strain sensitivity increases are $33.6 \%, 34.6 \%$, and $-7.2 \%$. When the mixing amount is $0.75 \%$, the carbon fiber bond in the cement group is relatively tight, the electronic transition is relatively simple, and there is no internal defect caused by the agglomeration phenomenon. A test piece with a CF content of $0.75 \%$ is more advantageous as a sensing material for detecting the health structure of cement-based materials. Under the action of large loads, the phenomenon of "bluntness" in pressure sensitivity appears. When the CF RPC is pressed, the distance between two adjacent CFs is reduced, the ability of electrons to transition is enhanced, the resistance is reduced, and the current is increased. With 


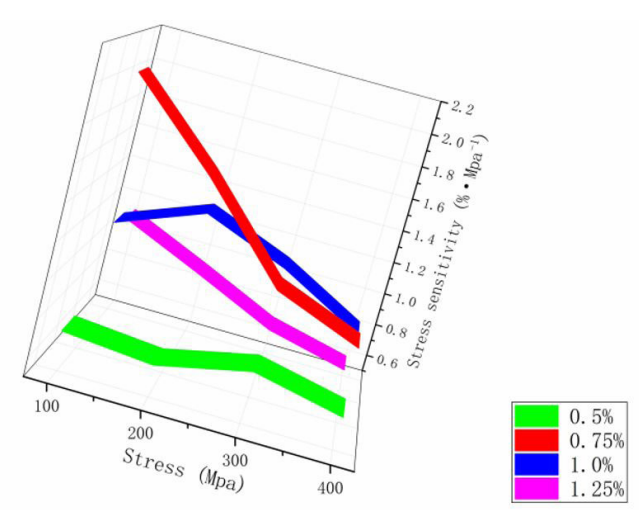

(a) Stress sensitivity under different CF content

Figure 10. Stress and strain sensitivity under different CF content

the increase of CF content and load, the overlap rate of $\mathrm{CF}$ is getting higher and higher, the electronic transition is relatively easy, and the degree of change in stress sensitivity and strain sensitivity gradually decreases. When the load amplitude increases to a critical value, a large number of conductive networks are formed inside the specimen. As the load gradually increases, the internal conductive network changes are not as obvious as initially, and the corresponding FCR is also less sensitive to changes in stress and strain. In a comprehensive way, specimens with fiber content of $0.75 \%$ have more advantages as cement-based materials for health structure detection and sensing.

\section{Conclusion}

When the CF content is in the range of $0 \%$ to $0.75 \%$, the compressive strength of the CF RPC increases with the increase of the $\mathrm{CF}$ content. When the CF content exceeds a critical value $(0.75 \%)$, The increasing rate of compressive strength of carbon fiber RPC decreased, but the strength was still better than that of raw RPC. With the increase of carbon fiber content, Poisson's ratio first increases and then decreases. The elastic modulus decreased first and then increased.

CF can effectively improve the conductivity of RPC. When the amount of CF in RPC is from $0 \%$ to $0.5 \%$, the resistivity of CF RPC is significantly reduced by $75.3 \%$. When the CF content is increased from $0.5 \%$ to $0.75 \%$, the resistivity of the CF RPC decreases by $97.7 \%$, As the carbon fiber content continues to increase, the resistivity will be flat and slightly increased.

In the range of $0-40 \mathrm{Mpa}$, as the load gradually increases, the FCR shows a gradually increasing change. When the CF content is $0.75 \%$, the maximum strain and FCR are $1.22 \times 10-2$ and $38.8 \%$, respectively, and the maximum FCR is increased by $33 \%$. When the fiber content exceeds $0.75 \%$, the content continues to increase, and FCR shows a gradually decreasing trend.

With the increase of carbon fiber content, the stress and strain sensitivity of carbon fiber RPC reached the best value at $0.75 \%$ content, reaching $2.05 \% / \mathrm{Mpa}$ and 386.1 respectively. CF RPC has a stable sensing function, and the

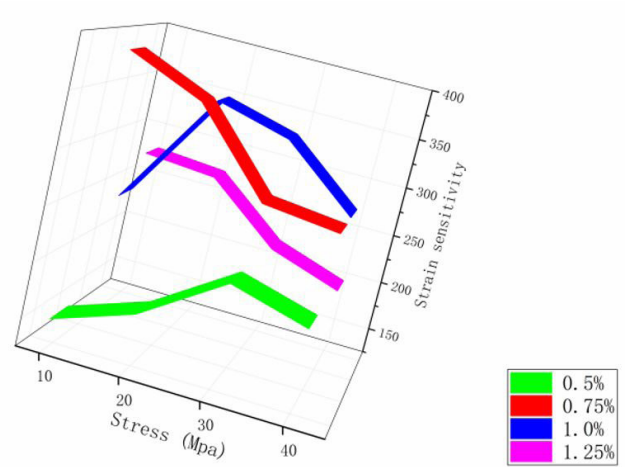

(b) Strain sensitivity at different CF content

stress/strain sensitivity during progressive loading gradually decreases. Under the action of large loads, "bluntness" in pressure sensitivity occurs.

\section{Acknowledgments}

The authors would like to thank the anonymous reviewers for their constructive suggestions and comments to improve the quality of the paper. This research was funded by the Science Technology Department Program of Jilin Province (grant no. 20190303138SF), the Science and Technology Project of Education Department of Jilin Province (grant no. JJKH20190875KJ), and the Science and Technology Project of Education Department of Jilin Province (grant no. JJKH20190870KJ).

\section{References}

1. Wong JKW, Li H, Wang SW. Intelligent building research: a review. Autom Construct. 2005;14(1):143-59.

2. Li H, Xiao HG, Ou J. Effect of compressive strain on electrical resistivity of carbon black-filled cement-based composites. Cement Concr Compos. 2006;28(9):824-8.

3. Liu XY, Yao W, Wu KR. Research on temperature sensitivity of carbon fiber cement-based composites. J Hohai Univ. 2007;2:202-4.

4. Nan XL, Li XM, Lu XF, Guo X. Discussion on the conductive mechanism of carbon fiber cement-based composites. J Lanzhou Univ Tech. 2012;38(2):114-9. In chinese.

5. Souza AT, Pereira RF Jr, Neuba LM, Candido VS, da Silva ACR, de Azevedo ARG, et al. Caranan Fiber from Mauritiella armata palm tree as novel reinforcement for epoxy composites. Polymers. 2020;12(9):2037.

6. Azevedo ARG, Marvila MT, Tayeh BA, et al. Technological performance of açaí natural fibre reinforced cement-based mortars. J Build Eng. 2020;33:101675.

7. Marvila MT, Azevedo ARG, Cecchin D, Costa JM, Xavier GC, Carmo DF, et al. Durability of coating mortars containing acai fibers. Case Stud Construct Mater. 2020;13:e00406.

8. Richard P. Reactive powder concrete:a new ultra-high-strength cementitious material. In: Proceedings of the 4th International Symposium on Utilization of High Strength/High Performance Concrete; 1996; Paris. Farmington Hills: American Concrete Institute; 1996. p. 1343-1349. 
9. Cheyrezy M, Maret V, Frouin L. Micro-structural analysis of RPC (reactive powder concrete). Cement Concr Res. 1995;25(7):1491-7.

10. Richard P, Cheyrezy M. Composition of reactive powder concretes. Cement Concr Res. 1995;25(7):1501-11.

11. Tan WC, Cao F. An ultra-high performance concrete: reactive powder concrete. Ind Archit. 1999;4:16-8. In chinese. http:// dx.doi.org/10.3321/ j.issn.1000-8993.1999.04.005.

12. Katz A, Bentur A. Mechanical properties and pore structure of carbon fiber reinforced cementitious composites. Cement Concr Res. 1994;24(2):214-20.

13. Ivorra S, Garcés P, Catalá G, Andión LG, Zornoza E. Effect of silica fume particle size on mechanical properties of short carbon fiber reinforced concrete. Mater Des. 2010;31(3):1553-8.

14. Xu JY, Li WM, Fan FL, Bai EL. SHPB experimental study on carbon fiber reinforced polymer concrete. J Build Mater. 2010;13(4):435-40. In chinese.

15. Shu X, Graham RK, Huang B, Burdette EG. Hybrid effects of carbon fibers on mechanical properties of Portland cement mortar. Mater Des. 2015;65:1222-8.

16. Meng W, Khayat KH. Mechanical properties of ultra-highperformance concrete enhanced with graphite nanoplatelets and carbon nanofibers. Compos, Part B Eng. 2016;107:113-22.

17. Rangelov M, Nassiri S, Haselbach L, Englund K. Using carbon fiber composites for reinforcing pervious concrete. Constr Build Mater. 2016;126:875-85.

18. Park SJ, Seo MK, Shim HB, Rhee K-Y. Effect of different crosssection types on mechanical properties of carbon fibers-reinforced cement composites. Mater Sci Eng A. 2004;366(2):348-55.
19. Li W, Zhu JH, Chen P, Xing F, Li D, Su M. Evaluation of carbon fiber reinforced cementitious matrix as a recyclable strengthening material. J Clean Prod. 2019;217:234-43.

20. Azhari F, Banthia N. Cement-based sensors with carbon fibers and carbon nanotubes for piezoresistive sensing. Cement Concr Compos. 2012;34(7):866-73.

21. Sassani A, Ceylan H, Kim S, Gopalakrishnan K, Arabzadeh A, Taylor PC. Influence of mix design variables on engineering properties of carbon fiber-modified electrically conductive concrete. Constr Build Mater. 2017;152:168-81.

22. Han B, Zhang L, Zhang C, Wang Y, Yu X, Ou J. Reinforcement effect and mechanism of carbon fibers to mechanical and electrically conductive properties of cement-based materials. Constr Build Mater. 2016;125:479-89.

23. Chiarello M, Zinno R. Electrical conductivity of self-monitoring CFRC. Cement Concr Compos. 2005;27(4):463-9.

24. Baeza FJ, Galao O, Zornoza E, Garcés P. Effect of aspect ratio on strain sensing capacity of carbon fiber reinforced cement composites. Mater Des. 2013;51:1085-94.

25. Hambach M, Möller H, Neumann T, Volkmer D. Carbon fibre reinforced cement-based composites as smart floor heating materials. Compos, Part B Eng. 2016;90:465-70.

26. Chinese Standard. GB175-2007: standard for common Portland cement. Beijing; 2007. In chinese.

27. Chinese Standard. GB/T51003/2014: technical code for application of mineral admixture. Beijing; 2014. In chinese.

28. Chinese Standard. GB/T31387-2015: standard for reactive powder concrete. Beijing; 2015. In chinese.

29. Han B, Ou J. Embedded piezoresistive cement-based stress/ strain sensor. Sens Actuators A Phys. 2007;138(2):294-8. 